\title{
Forests in focus
}

\author{
In light of the urgent need to mitigate climate change, many governments and companies are looking to the natural \\ world for help, most notably through plans to plant forests to remove carbon from the atmosphere. However, the
} carbon - and social — dynamics of forests are complex.

T he terrestrial biosphere takes up approximately one-third of anthropogenic carbon emissions, and forests alone represent a net sink for around $7.6 \mathrm{GtCO}_{2}$ equivalents annually. ${ }^{1}$ Yet, forests are under threat from disturbances that are exacerbated by climate change, as well as human pressures and deforestation. Nevertheless, afforestation plans are underway to increase forest cover and $\mathrm{CO}_{2}$ uptake. In this issue of Nature Climate Change and in an online collection, we feature research and opinion content focusing on the scientific, practical and human issues surrounding carbon storage in forests and their use as a natural solution to climate change.

Curbing emissions from land use and forestry and enhancing terrestrial carbon uptake are key to progress toward the Paris Agreement temperature goals, which is to be assessed in a Global Stocktake commencing in 2022. However, $\mathrm{CO}_{2}$ emission estimates from models used to gauge mitigation progress (Integrated Assessment Models) and countries' inventories (national GHG inventories) that are used to determine mitigation targets do not match. This is related to differences in how models and countries classify emissions from land caused by people, which includes forestry. In their Article, Giacomo Grassi and colleagues point to a short-term solution to this mismatch so that progress can be accurately measured in time for the Stocktake. This is further explored in an associated News \& Views by Stephen Ogle and Werner Kurz.

Rising pressures on natural forests make managing terrestrial carbon storage particularly difficult. Although productivity has increased as a result of rising $\mathrm{CO}_{2}$ levels in the atmosphere ${ }^{2}$, other consequences of climate change are negatively impacting forests and their ability to take up and sequester carbon. For example, disturbance to forests from fires and timber harvest reduces carbon uptake in boreal forests, some of the most carbon dense forests, as shown in an Article by Jonathan Wang and colleagues. In another Article, Xiangming Xiao and others show for the Brazilian Amazon that, although deforestation leads to greater loss

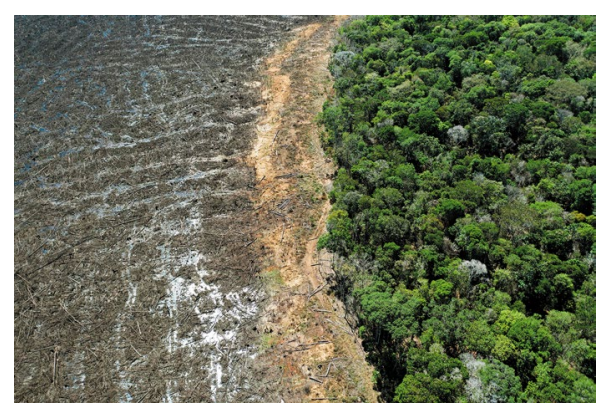

Credit: FLORIAN PLAUCHEUR / Contributor / AFP/Getty

of forest area, degradation has a stronger impact on biomass - and carbon storage. A similar picture arises on the African continent, where less is known about carbon storage potential, in a fourth Article by Wade Ross et al. Although the impacts are heterogeneous, climate change and anthropogenic activities are projected to negatively influence woody biomass.

Deforestation is a major concern, both for environmental and human health, being linked to disease outbreak ${ }^{3}$, as well as for its impact on climate change. A report recently released from the World Resources Institute indicates that loss of primary rainforest increased by $12 \%$ between 2019 and 2020 , with Brazil and Indonesia leading the list of countries with most loss in the twenty-first century ${ }^{4}$. In their Correspondence, Luís Guedes Pinto and Mauricio Voivodic draw attention to the Brazilian Atlantic Forest, calling for a halt to deforestation and for restoration of the forest, highlighting existing policy that would support recovery.

Despite increases in primary forest loss, in many cases driven by land-use conversion for commodity production, plans to plant additional forests are being pursued as a mitigation strategy for countries and companies working toward net-zero targets. However, increasing forest cover so that it has a real impact on climate is not straightforward. In addition to degradation, research is emerging around the social and practical aspects that make large-scale afforestation difficult, which are highlighted in a Feature in this issue.
One concern is that measuring the impact of such plans is a challenge. Susan Cook-Patton and colleagues set out a framework for dynamic global monitoring and coordination in their Comment, which they stress are required to assess the progress of restoration projects. Furthermore, such projects need to consider the rights and needs of local communities. Ensuring the rights of Indigenous communities and considering the impacts of afforestation on gender inequality must be a key component of land-based climate solutions, argue Juliana Nnoko-Mewanu and colleagues. Excluding women and Indigenous peoples from such plans is not only problematic from a human rights perspective, it is also a less effective mitigation strategy.

In addition to planting new forest, slowing - or halting - primary forest loss is a powerful strategy for mitigating climate change. Multiple studies, including a recent $\mathrm{FAO}$ report ${ }^{5}$, have shown that areas inhabited by Indigenous people experience much lower rates of deforestation, even in comparison to other protected areas. In a Q\&A, Michael Finley, Michael McGarrell and Paul Redmond share their perspectives as Indigenous people from forest communities and as entrepreneurs, underlining the role of Indigenous people in solving the climate crisis.

The land sector, including forests, does and likely will continue to play a large role in the trajectory of climate change in the near future, as well as in mitigation strategies as countries work to limit warming. These collective facets of forest carbon storage are therefore important considerations going forward. However, it is imperative to simultaneously balance such mitigation with reduction in GHG emissions, including those stemming from loss of primary forests.

Published online: 6 May 2021

https://doi.org/10.1038/s41558-021-01050-5

References

1. Harris, N. L. et al. Nat. Clim. Change 11, 234-240 (2021).

2. Schimel, D. et al. Proc. Natl Acad. Sci. USA 112, 436-441 (2015).

3. Morand, S. \& Lajaunie, C. Front. Vet. Sci. 8, 661063 (2021).

4. Global Forest Review (World Resources Institute, 2021).

5. Forest Governance by Indigenous and Tribal Peoples. An Opportunity for Climate Action in Latin America and the Caribbean (FAO and FILAC, 2021); https://doi.org/10.4060/cb2953en 